\title{
Direct probing of semiconductor barium titanate via electrostatic force microscopy ${ }^{*}$
}

\section{(Sondagem direta de titanato de bário semicondutor por meio de microscopia de força eletrostática)}

\author{
S. M. Gheno ${ }^{1}$, H. L. Hasegawa ${ }^{1,2}$, P. I. Paulin Filho ${ }^{1}$ \\ ${ }^{1}$ Departamento de Engenharia de Materiais, Universidade Federal de S. Carlos \\ Rod. Washington Luiz, km 235, C.P. 676, S. Carlos, SP 13565-905 \\ ${ }^{2}$ ECIL Met. Tec. Ltda., R. Benjamin da Silveira Baldy 2001, Paulas e Mendes, Piedade, SP 18170-000 \\ gheno@dema.ufscar.br
}

\begin{abstract}
Electrostatic force microscopy (EFM) was used to directly probe surface potential in doped barium titanate semiconducting ceramics. EFM measurements were performed using noncontact scans at a constant tip-sample separation of $75 \mathrm{~nm}$ with varied bias voltages applied to the sample. The applied voltage was mapped up to $10 \mathrm{~V}$ and the distribution of potential across the sample showed changes in regions that matched the grain boundaries, displaying a constant barrier width of $145.2 \mathrm{~nm}$.
\end{abstract}

Keywords: electrostatic force microscopy, electric potential, barriers, barium titanate

\section{Resumo}

A microscopia de força eletrostática (EFM) foi usada para sondagem direta do potencial na superfície do titanato de bário dopado, o qual é cerâmica semicondutora. As medidas de EFM foram realizadas no modo não contato, mantendo a distância ponta-amostra de $75 \mathrm{~nm}$ constante, mas variando a voltagem bias aplicada à amostra de zero a $10 \mathrm{~V}$. A distribuição do potencial na amostra mostrou mudanças em regiões próximas ao contorno de grão, exibindo largura de barreira constante de 145,2 $\mathrm{nm}$.

Palavras-chave: microscopia de força eletrostática, potencial elétrico, barreiras, titanato de bário

\section{INTRODUCTION}

The ferroelectric properties were discovered at approximately 75 years ago [1], and the ability of ferroelectric materials to sustain spontaneous polarization below the Curie temperature remains one of the most fascinating features of Physics and also constitutes the basis for their wide technological applicability [2, 3].

Ferroelectric barium titanate, $\mathrm{BaTiO}_{3}$, is typically used as the base material for non-linear positive-temperature coefficient (PTC) resistors [4-8]. Barium titanate exhibits intrinsic resistivity $>10^{10} \Omega \cdot \mathrm{cm}$, when preparated in an oxidizing atmosphere. Through controlled A-site doping using ions such as $\mathrm{La}^{3+}, \mathrm{Y}^{3+}, \mathrm{Nd}^{3+}$ or B-site doping using ions $\mathrm{Ta}^{5+}$, semiconducting properties can be obtained [8]. Donor-doped $\mathrm{BaTiO}_{3}$ can be semiconducting and shows a positive temperature coefficient. These behaviors are accounted for by the incorporation of donors [4-5]. However, as the concentration of donors increases, a transition from semiconducting to insulating behavior occurs.

*Apresentado no $V$ Encontro da Sociedade Brasileira de Pesquisa em Materiais, Florianópolis, SC (2006)
Ceramics based on doped barium titanate are ferroelectric polycrystals exhibiting a widevariety of electrical phenomena, which are commonly employed in applications such as sensors and actuators due to their wide variations in electrical resistance as a function of temperature [4-7]. The electronic characteristics of many electronic ceramics are determined by grain boundaries and grain boundary states. For example: the temperature dependence of donor-doped $\mathrm{BaTiO}_{3}$ based PTC thermistor ceramics is determined by acceptor states at the grain boundaries [8]. These behaviors are accounted for by the incorporation of donors. It has been accepted that the PTC in donor-doped $\mathrm{BaTiO}_{3}$ originates from the potential barrier that is formed at the grain boundaries increasing the electrical resistance $[4-8,10,11]$. These materials display an electrical behavior characterized by an abrupt increase in resistivity as a function of temperature close to the Curie temperature $\left(T_{C}\right)[7,8,11]$. This effect occurs in barium titanate during the shift from cubic to tetragonal phase when cooling to temperatures below $130^{\circ} \mathrm{C}$ and it is a grain boundary effect that depends strongly on the microstructure [11-15]. The most widely accepted models attribute the PTC phenomena to the formation of potential barriers at grain boundaries, increasing the resistivity when temperatures 
above $130{ }^{\circ} \mathrm{C}$ are reached. This is a grain boundary effect and depends strongly on microstructure; therefore, the electric properties of ceramic PTC can be observed through the grain boundaries and their levels of energy [13-18].

Several techniques have been used to characterize the PTC effect on grain boundaries: scanning probe microscopy (SPM) based techniques, namely intermittent mode atomic force microscopy (IC-AFM) [19, 20] and especially different variants of SPM, just as electric force microscopy (EFM) [21-23], which can be successfully employed as an analytical technique capable of mapping the electrical properties of a material by monitoring the attractive and repulsive interactions between a sharp conductive tip and a sample. While the intermittent contact mode technique provides information on the topographic structure the EFM image provides more direct information on the local potential of the surface. Analysis in the vicinity of the resonant frequency of the cantilever is complex due to the resonant frequency shift of the cantilever induced by electrostatic force gradients [24].

The objective of the present research is to investigate the effect of electric properties in yttrium doped-barium titanate using the intermittent mode atomic force microscopy combined with electric force microscopy by gradient applications of electric field.

\section{EXPERIMENTAL}

\section{Materials and equipment}

Yttrium-doped barium titanate (YBT) was obtained by mixing $0.3 \%$ of yttrium nitrate $\left(\mathrm{Y}_{\left(\mathrm{NO}_{3}\right)}\right)_{3} \cdot 6 \mathrm{H}_{2} \mathrm{O}, 99.8 \%$, AESAR, with $\mathrm{BaTiO}_{3}$ powder with $[\mathrm{Ba}] /[\mathrm{Ti}]=0.95$ (TAM ceramics). The mixture was made in an aqueous solution and dried to a powder, which was then ground and compacted into pellets. These pellets were sintered at $1350{ }^{\circ} \mathrm{C}$ for $2 \mathrm{~h}$ and their grains revealed by thermal attack at $1250^{\circ} \mathrm{C}$ for 1 min. EFM experiments were performed using a Dimension 3000 Atomic Force Microscope equipped with a Nanoscope III controller and an Extender Electronics Module (Veeco Instruments). NSC15/50 silicon cantilevers coated with $\mathrm{Co} / \mathrm{Cr}$ layer were obtained from MikroMasch, with spring constant of $2.8 \mathrm{~N} / \mathrm{m}$. The resonance frequency of the cantilever was measured to be $25 \pm 2 \mathrm{~Hz}$.

\section{EFM experiment}

In the EFM measurements, two-pass scans are used in order to minimize the topography effects on the electrostatic force gradient signal. During the first pass, the topographical profile is obtained by intermittent contact of the tip with the surface of the sample because in many cases, the macroscopic properties of ceramics are determined by the microstructure, particularly by grain boundary structure and topology. The tip is then lifted to a predetermined height, and a second scan is performed at a constant separation between the tip and the biased surface of doped-barium titanate. The tip-sample separation is maintained constant by following the topographical profile of the sample. During the second scan the interaction between the tip and the biased sample influences the oscillation frequency of the vibrating cantilever are measured. Variations in frequency shifts are then detected and processed to generate electrostatic force gradient images. The separation distance of 75 nanometers between the tip and the sample was chosen in order to minimize the effect of the van de Waals forces while allowing the monitoring of the long range electrostatic forces. Electrostatic force gradient images were obtained by monitoring the shifts in frequency between the oscillations of the AFM cantilever and those of the piezoelectric driver as a function of bias voltages applied to the sample. The EFM images of surface potential were obtained by applying 0,4 and $10 \mathrm{~V}$ in situ on the sample.

\section{RESULTS AND DISCUSSION}

Fig. 1 shows the characteristic PTC curve of YBT. The electrical resistivity of YBT at temperatures below $85^{\circ} \mathrm{C}$ behaves like that of any semiconductor with a negative temperature coefficient. A sharp PTC effect of 3 orders magnitude starting at $\sim 85^{\circ} \mathrm{C}$ and ending at $\sim 130^{\circ} \mathrm{C}$ was observed. In this region the resistivity increased exponentially with the temperature. This abrupt increase in resistivity was attributed to the shift from tetragonal phase (ferroelectric) to cubic phase (paraelectric), evidencing the PTC effect. The ferroelectric domains, which short-circuited the grain boundary, disappeared gradually as the temperature rose. At temperatures exceeding $130{ }^{\circ} \mathrm{C}$ the resistivity values declined once more and the NTC effect became predominant. Low resistivity at high temperatures is caused by the desorption of chemisorbed oxygen atoms at the grain boundaries upon heating, which diminishes the potential barrier height. Thus, chemisorbed oxygen is consumed and conducting electrons are released, lowering the potential barrier and degrading the PTC effects [25].

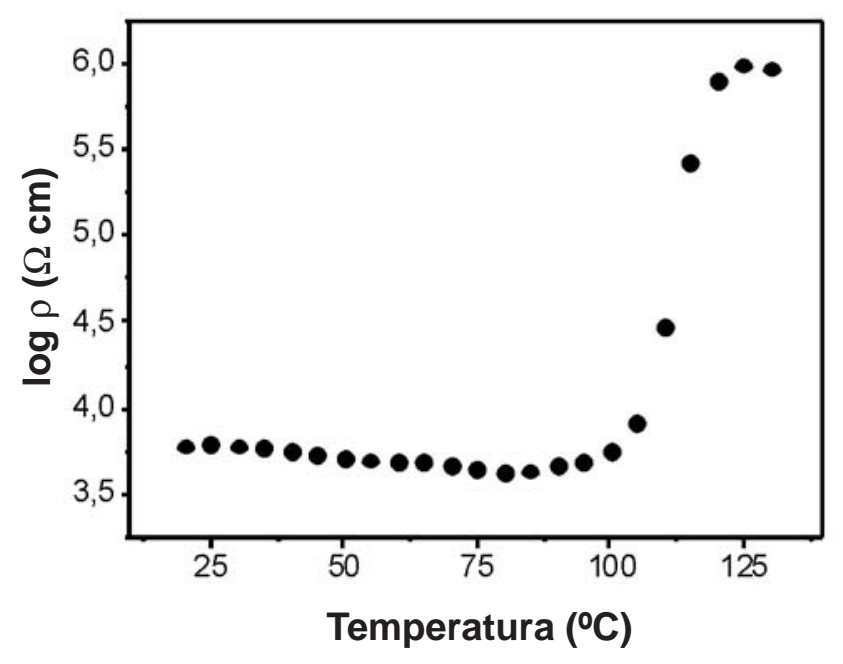

Figure 1: Characteristic curve of resistivity log versus temperature for YBT.

[Figura 1: Curva característica para YBT: logaritmo da resistividade versus temperatura.] 
The topography and EFM images were recorded simultaneously to characterize the local ferroelectric properties.

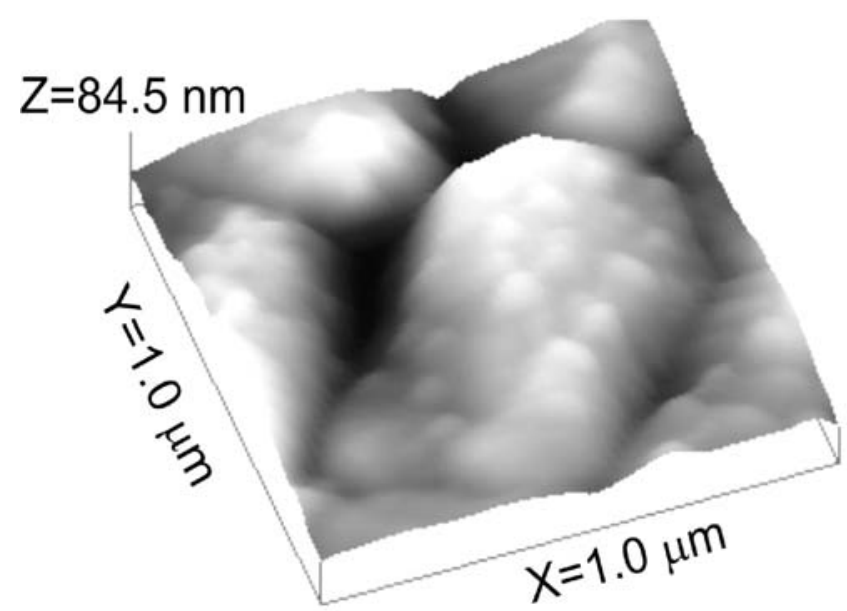

Figure 2: FM topographic image of YBT.

[Figura 2: Imagem topográfica do YBT obtida no AFM.]

Fig. 2 shows the topographic AFM image of yttriumbarium titanate (YBT), revealing a microstructure with clearly defined grains and grain boundaries.

Fig. 3 shows the EFM image corresponding to the topographical image of YBT obtained by AFM and shown in Fig. 2. The sample was subjected to a range of voltages from 0 to $10 \mathrm{~V}$ while the EFM scan was performed at a $75 \mathrm{~nm}$ lift height. Fig. 3a shows the EFM image without the applied voltage gradient, showing no features when compared with Fig. 2 while Fig. 3b shows EFM images with $10 \mathrm{~V}$ applied on the sample surface. These EFM images clearly show the raising of potential barriers as the applied field gradient increased.

No variations occurred in the potential barriers at the grain boundaries at $0 \mathrm{~V}$ (Fig. 3a). As the applied voltage at $10 \mathrm{~V}$ (Fig. 3b) the grain boundaries are clearly visible and were found to be congruent with the topographic image depicted in Fig. 2.

The dark regions starting in Fig. $3 \mathrm{~b}$ are associated with semiconductor material, indicating that the grains are current conductors, while the bright regions are insulating regions associated with grain boundaries. These images were formed because, as the voltage increased, the probe began to be repelled in the grain boundary regions. This is congruous with theories developed to explain the PTC behavior observed in doped barium titanate, and indicates that the PTC effect is related to the barrier formed at the grain boundaries in response to segregation of acceptor and donor dopants.

To quantify the minimum error in the elimination of topographic signals in the potential gradient image, a comparison was made of the topographic image and the potential gradient image at the interface of some grain boundaries. Since there is no lateral applied voltage, the features at the grain boundaries increase as the repulsive forces increase between the grain boundary and the force probe.

The potential barrier trend shown in Fig. 3 can be quantified by extracting profiles in the same position in each image. The image contrast in Fig. 4 emphasizes the fact that the increase of contrast in the field gradient image is not due to the topographical structure but to effects of the local electric field. An increase in the voltage applied on the sample's surface corresponds to an increase in the local field
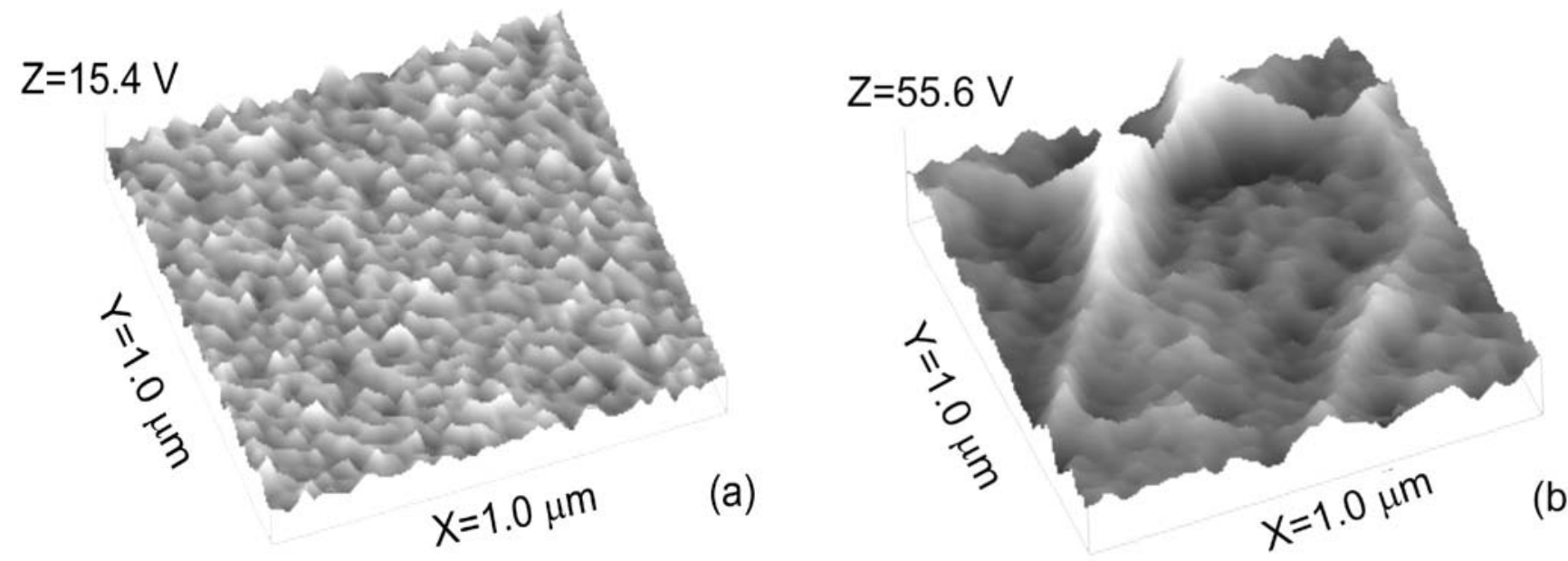

Figure 3: EFM image profiles of YBT: (a) without external applied voltage; (b) with $10 \mathrm{~V}$ of external applied voltage. [Figura 3: Perfis de imagens EFM do YBT: (a) sem voltagem externa aplicada; (b) com voltagem externa de 10 V.] 
gradient. In either case, the results shown in Fig. 4 imply that the voltage drop at the grain boundary spreads extensively into the grain.

The EFM results indicate that the height of the field gradient is strongly dependent on the applied voltage. The width of the region over which the voltage changes near an interface is a function of the material's parameters and is not expected to be very sensitive to the applied voltage $[4,5]$. The measured barrier width was $145.2 \mathrm{~nm}$, which is close to the values reported in the literature $[15,17,26]$.

The resistivity of the barrier layer depends on both the geometry and the activation energy required to surmount the height of the potential barrier. The resistivity anomaly of the barrier layer is due to a decrease in carrier density rather than in carrier mobility. The depletion of free charge carriers applies in the same way to volume and barrier layers.

The grain boundary dependence of PTC effect demonstrated in Fig. 1 suggests that grain boundary can be affecting the oxidation behavior, because of the change in diffusivity. Such a secondary effect that is associated with the atomic structure of grain boundaries will be crucial to the formation of the potential barrier in doped barium titanate.

With the potential barrier data presented in Fig. 4, the resistivity anomaly can be treated quantitatively, according to Heywang's theory [4]. We therefore propose a band diagram for YBT (Fig. 4) that show the height of the potential barrier $\left(\phi_{0}\right)$ which controls the resistance of a sample, defects at the grain boundary produces a density of interface acceptor states $\left(\mathrm{N}_{\mathrm{s}}\right)$ and the energy depth of the states from bottom conduction band $\left(\mathrm{E}_{\mathrm{s}}\right)$ distributed over a certain energy range.

In this situation, the value of $\mathrm{E}_{\mathrm{s}}$ can be approximated approximated by the sum of the potential barrier height and the difference between bottom of the conduction-band Fermi level at the inner grains $\left(\mathrm{E}_{\mathrm{F}}\right)$. In the volume of the $\mathrm{BaTiO}_{3}$ grains, electron donors embodied in the lattice dissociate quantitatively above ambient temperature. Our results demonstrate that both donors and acceptors segregate in the boundary region, in agreement with Heywang [41] and Desu \& Payne [18, 20].

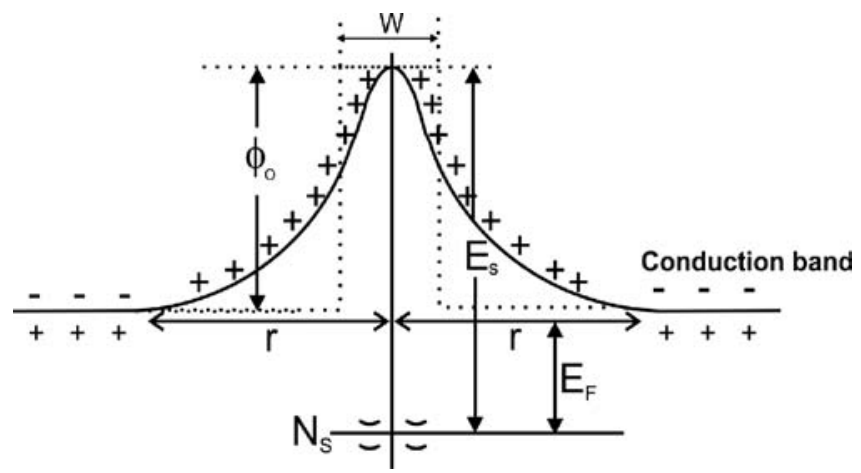

Figure 4: Schematic representation of the PTC barrier model with external voltage ( $\phi_{0}$ : potential barrier).

[Figura 4: Representação esquemática do modelo de barreiras para PTC com a voltagem externa $\left(\phi_{0}\right.$ : barreira de potencial.]
Theories on the PTC effect suggest that a space charge or barrier layer is produced as electrons move toward the grain boundary, which acts to repel the electron flux. At temperatures below the critical ferroelectric phase transition, low resistivity is found due to $(+)$ spontaneous polarization charges neutralizing (-) grain boundary charges in crystallographically coherent areas along the grain boundaries, creating a low resistance path [4, 27, 28].

Electron trapping due to vacancies and acceptors depends on dopant segregation, which, in turn, depends on thermal treatment conditions. Defects and diffusion effects suggest that the potential barriers originating at the grain boundaries are due to regions of barium-rich vacancies that are electrically compensated by electron donors (oxygen diffusion along grain boundaries). However, acceptor and donor dopants are assumed to be uniformly distributed throughout the grains and grains boundaries and the acceptor effects are due to their activation energies. Dopant mass transport is driven by differences in the surface and interface energies, which lead to nonuniform distribution of dopants and, as such, need not be symmetric around the boundary. Activation energies depend on polarization in the ferroelectric region, and the formation of high electrical resistance regions at grain boundaries produces potential barriers. Space charges are developed in the vicinity of grain boundaries due to the flow of electrons from the conducting grains to the vicinity of the high resistance area (grain boundaries) [4, 12, 13, 27, 28].

Donor or acceptor dopants are assumed to be uniformly distributed throughout the grains and grain boundaries and the acceptor effect is only interpreted through their energy levels. The activation energy can be expressed as a function of polarization in the ferroelectric area. If the traps in the grain boundary are activated, some of the carriers contributed by the donor atoms in the grain may be trapped at the grain boundaries, thus producing a region of space with the opposite polarity. The thickness and resistivity of the space charge region, and the grain-boundary resistive region, can then limit the sample's conductivity. The results obtained here with EFM are only in partial agreement with Desu and Payne's theory $[9,10]$, since we did not find any variation in barrier layer width.

Therefore, space charges will develop in the vicinity of grain boundaries in response to the flow of electrons from the core of the semiconducting grain to its highly resistive boundary. Space loads are developed in the neighborhood of the grains' applied voltage limit (10 Volts) due a flow of electrons starting from inside the semiconducting grains to regions of high resistivity in their vicinity. This transition has been explained in terms of constant width layer of the space load, independent of grain size [6, 11, 13, 17].

\section{CONCLUSION}

The EFM results provide strong support to explain the PTC effects in YBT ceramics, showing the formation of potential barrier in grain boundary regions and a resistivity layer associated with space charge regions. Despite our detailed discussion of all 
the physical details obtained with the aid of the grain boundary barrier layer model, it should be emphasized that the surface states have only been introduced phenomenologically and that very little is known about their nature. This justifies the assumption that the chemical conditions at the grain boundary play an important role in the surface states, based on the fact that YBT containing $0.3 \mathrm{wt} \%$ of yttrium displayed a resistivity anomaly of 3 orders of magnitude. The measured potential barrier width was $145.2 \mathrm{~nm}$.

\section{ACKNOWLEDGEMENTS}

We gratefully acknowledge CAPES (Brazil) for the financial support and the National Synchrotron Light Laboratory (LNLS) (Campinas, SP, Brazil) for the atomic force microscopy analyses.

\section{REFERENCES}

[1] J. Valasek, Phys. Rev. 17 (1921) 475.

[2] L. L. Hench, J. K. West, Principles of Electronic Ceramics, Wiley, New York (1990).

[3] Ferroelectric Ceramics, Eds. N. Setter, E. L. Colla, Birkhauser, Basel, Germany (1993).

[4] W. Heywang, J. Am. Ceram. Soc. 47, 10 (1964) 484490.

[5] G. H. Jonker, Solid State Electronics 7 (1964) 895-903.

[6] J. Shieh, J. E. Huber, N. A. Fleck, Acta Materialia 51 (2003) 6123-6137.

[7] N. Kataoka, K. Hayashi, T. Yamamoto, Y. Suguwara, Y. Ikuhara, T. Sakuma, J. Am. Ceram. Soc. 81 (1998) 19611963.

[8] J. Daniels, K. H. Hzrdtl, Philips Research Report 31 (1976) 489.

[9] B. Kulwicki, Advances in Ceramics, Ed. L. Levinson 1 (1981) 138-154.

[10] J. Seaton, C. Leach, Acta Materialia 51 (2003) 6027-
6034.

[11] J. Seaton, C. Leach, Acta Materialia 53 (2005) 27512758.

[12] S. B. Desu, D. A. Payne, J. Am. Ceram. Soc. 73, 11 (1990) 3416-3417.

[13] S. B. Desu, D. A. Payne, J. Am, Ceram, Soc. 73, 11 (1990) 3398-3406.

[14] K. Hayashi, T. Yamamoto, T. Sakuma, J. Am. Ceram. Soc. 79 (1996) 1669-1672.

[15] K. Hayashi, T. Yamamoto, Y. Ikuhara, T. Sakuma, J. Appl. Phys. 86 (1999) 2909-2913.

[16] J.-H Chen, B.-H. Hwang, T.-C. Hsu, H.-Y. Lu, Mater. Chem. and Phys. 91, 1 (2005) 67-72.

[17] K. Hayashi, T. Yamamoto, Y. Ikuhara, T. Sakuma, J. Am. Ceram. Soc. 83 (2000) 2684-2688.

[18] S. B. Desu, D. A. Payne, J. Am. Ceram. Soc. 73, 11 (1990) 3391-3397.

[19] Y. G. Wang, J. Dec, W. Kleemann, J. Appl. Phys. 84 (1998) 6795.

[20] M. Takashige, S.-I. Hamazaki, F. Shimizu, S. Kojima, Ferroelectrics 196 (1997) 211.

[21] R. Luthi, H. Haefke, K.-P. Meyer, E. Meyer, L. Howald, H.-J. Guntherodt, J. Appl. Phys. 74 (1993) 7461.

[22] L. M. Eng, J. Fousek, P. Gunter, Ferroelectrics 191 (1997) 211.

[23] S. M. Gheno, H. L. Hasegawa, V. L. Pimentel, P. I. Paulin Filho, J. Mater. Sci. 40, 17 (2005) 4461-4463.

[24] D. Sarid, Scanning Force Microscopy, Oxford University Press, New York (1991).

[25] J-G. Kim, W-S. Cho, K. Park, Mater. Sci. Eng. B 83 (2001) 123-129.

[26] S. B. Desu, D. A. Payne, J. Am. Ceram. Soc. 73, 11 (1990) 3391-3397

[27] R. W. Newnham, J. Mater. Educ. 6, 5 (1984) 806-839.

[28] J. D. Russell, C. Leach, J. Eur. Ceram. Soc. 15 (1995) 617-622.

(Rec. 15/10/2006, Ac. 16/03/2007) 